\title{
Potential and limits of Blockchain technology for networked businesses
}

\author{
Roger W.H. Bons ${ }^{1} \cdot$ Johan Versendaal ${ }^{2} \cdot$ Liudmila Zavolokina $^{3} \cdot$ Weidong Larry Shi ${ }^{4}$
}

Received: 1 April 2020 / Accepted: 3 April 2020 / Published online: 21 April 2020

(C) The Author(s) 2020

\section{Introduction}

New ways to organize economic activities are emerging, facilitated by Blockchain technology or the broader term Distributed Ledger Technology. Blockchains consist of dynamic shared ledgers that can be applied to ensure transparency and traceability and to save time when recording transactions between parties, remove costs associated with intermediaries (or, according to Nakamoto (2008), remove the need for intermediaries altogether), while enabling the introduction of pseudonymous parties on the Internet. First, and probably the most known application of blockchain technology, is cryptocurrency, such as Bitcoin. It has taken businesses and industries some time to recognize that the underlying technology of Bitcoin could be the next wave for disruption of their existing business models. All too often, the focus of the media coverage is on the connection of cyber-currencies to criminal activities or on the highly speculative nature of their exchange rates and issues with coin exchanges.

This article is part of the Topical Collection on Potential and Limits of Blockchain Technology for Networked Businesses

Roger W.H. Bons

roger.bons@fom.de

Johan Versendaal

johan.versendaal@ou.nl

Liudmila Zavolokina

zavolokina@ifi.uzh.ch

Weidong Larry Shi

wshi3@central.uh.edu

1 FOM University of Applied Sciences, Essen, Germany

2 Open University, Heerlen, The Netherlands

3 Department of Informatics, University of Zurich, Zürich, Switzerland

4 University of Houston, Houston, TX, USA
In this Special Issue, we qualify this disruptive potential, as we recognize that Blockchain technology has much broader and deeper applications than "just" currencies. We take a broad and neutral view on the technology and consider it a facilitator for new coordination mechanisms for networked businesses. The transparency of the system and the assurance that all participants will play by the rules takes the "markets versus hierarchies" discussion to the next level, when electronic markets can be created that are not governed by a single centralized entity, but rather by the community they serve and that might exist only in the virtual space - implemented as "Distributed Autonomous Organizations (DAOs)", where "the code is the entire company" (Diedrich 2016). This might very well lead to completely different roles for current players, if not extinction.

Blockchains might thus facilitate and contribute to other disruptive innovations, such as the sharing economy, the circular economy as well as smart grids that help businesses and private households to become independent in their energy provisioning. The challenge for scientists now is to distinguish between the hype and the core value of this phenomenon, to reason about and to reflect on the business potential, including the potential to disrupt trusted business models, but also to address some of the deeper technical foundations such as scalability, accountability, and security. This is the time for research to explore descriptive, explanatory and design research questions on Blockchain technology.

\section{Terminology and concept}

The Call for Papers that we issued back in 2018 suggested a range of possible research topics, investigating various dimensions of the impact of Blockchain technology on electronic markets and networked businesses. The theme fits very well in the longstanding tradition of the Electronic Markets Journal in "recognizing the transformational role of information and communication technology in changing the interaction 
between organizations and customers" (Scope Statement of Electronic Markets). Similar to other 'disruptive' technologies that appeared since the first issue of the journal in 1991, such as 'Electronic Data Interchange (EDI)', 'Internet', 'Mobile Technology', 'Social Media', or 'Big Data', the purpose for this Special Issue is not to promote a technology push, but rather to investigate the emerging technology's potential impact on how organizations inter-operate through electronic markets.

A factor that most disruptive technologies have in common, at least at the beginning, is the confusion about definitions and a strong positioning against the status quo. For instance, in the 1990s, when the Internet started to appear on the radar of companies, a discussion erupted focusing on 'EDI versus the Internet', claiming that EDI was very much something from the past and would be replaced entirely by the Internet. It took a few valuable years before science and practice were able to properly define and position the two 'phenomena' as complementary, combining the knowledge and standards developed in the 'EDI' community with the efficiency of the Internet as a data delivery mechanism and the ubiquitous syntax of XML. Blockchain may suffer from similar issues, in this case induced by its standing as a technology invented to circumvent authorities and to obliterate intermediaries such as banks or even governments. There is a real risk, that the benefits for companies and societies as a whole may be obscured by this strong positioning, without awareness that 'old' and 'new' technologies may very well complement one another.

Unclarities in definitions and positioning might be the reason that after more than 10 years since the first Bitcoin was exchanged, papers related to Blockchain still, more often than not, contain small tutorials on what the technology is and how it will work. The first article in this issue, "Blockchain in the IS research discipline: a discussion of terminology and concepts", by Nadine Ostern (2020) addresses this gap between the high expectations of the Blockchain technology on the one hand and the lack of convincing real-world applications beyond cryptocurrencies on the other. In particular, this has created a debate on the role of IS research in shaping the future of blockchain technology. The article presents a systematic literature review of the AIS Library to address the presence of terminological ambiguities, concept proliferation and conceptual inconsistencies and finally technological determinism. These issues have to be clarified by IS research in order to make reliable predictions about compelling use cases of Blockchain.

\section{Information asymmetry and uncertainty}

Two important factors that can negatively affect the acceptance of an electronic market are information asymmetry and the level of uncertainty involved in the market environment.
We distinguish between on the one hand information asymmetry and uncertainty within the market, affecting the effectiveness and fairness of the transactions produced in the market and information asymmetry and uncertainty for investors in the platform itself on the other. The role of Blockchain technology in reducing either factor in either situation is investigated in this Special Issue.

We first look at the issues that might occur between buyers and sellers in (electronic) markets in the contribution by Ingrid Bauer, Liudmila Zavolokina and Gerhard Schwabe (2020). Their article "Is there a market for trusted car data?" addresses the information asymmetry between buyers and sellers, resulting in uncertainty and distrust and ultimately, inefficiencies of (electronic) markets. They investigate, whether the use of Blockchain technology can remedy these issues, based on the example of an electronic used car market, where the risk of buying a "lemon" - a product that has a much lower quality than advertised - is traditionally relatively high. The authors have run a market game with 50 participants and explored the effects of trusted car data on the sales price of cars and the revenue distribution between buyers and sellers. The research is part of larger action research project called "Cardossier".

A second article from this research project is presented by Liudmila Zavolokina, Gianluca Miscione and Gerhard Schwabe (2020). Whereas the first article focuses on the information asymmetries between buyers and sellers, the article "Buyers of 'lemons': How can a blockchain platform address buyers' needs in the market for 'lemons'?" addresses the quality uncertainty aspect. Buyers revert to information seeking to reduce their uncertainty and blockchain technology might play a role in automating the tracking of cars during their lifecycle and provide reliable information when needed. The authors have used a tri-angulated mixed-method approach using qualitative and quantitative methods to gain a reliable interpretation of used car buyers' information behaviors.

Finally, the third article in this cluster addresses information asymmetry during the start-up phase of a Blockchain venture, where the necessary funds have to be attracted to implement the Blockchain initiative. In their article "The behavior of blockchain ventures on Twitter as a determinant for funding success", Simon Albrecht, Bernhard Lutz and Dirk Neumann (2020) investigate the information asymmetry and uncertainty facing investors in non-regulated Initial Coin Offerings (ICOs), the financial instrument typically used to provide funding for Blockchain ventures. In particular, they employ methods from natural language processing to look at how positive language, time framing and interactivity levels on Twitter affect the level of uncertainty and consequently funding in an empirical study of 144,492 tweets connected to 522 blockchain ventures. 


\section{The role of "trust in technology" and how such trust can be built}

Trust has been a recurring theme for Electronic Markets. Today, trust underlies all economic transactions in the presence of uncertainties. A widely adopted definition of trust, suggested by (Rousseau et al. 1998) and used by Mayer et al. (1995, p. 712), that we refer to is "trust [...] is the willingness of a party [trustor] to be vulnerable to the actions of another party [trustee] based on the expectation that the other will perform a particular action important to the trustor, irrespective of the ability to monitor or control that other party." In recent years, digitalization has made trust in IT important, because modern technologies mediate the way we transact today. Furthermore, trust in IT is crucial for technology adoption (McKnight 2005). The 2014 Electronic Markets Special Issue on Security and Privacy in Business Networking (Wohlgemuth et al. 2014) is of particular relevance in this context. It introduced a view on "achieving acceptable secure business networking applications in spite of threats due to covert channels". IT security can be enforced by adapting resilience in business networking applications.

In the previous section, we discussed information asymmetry and uncertainty, topics closely related to trust. When organizations and/or people trust each other, for instance because they have successfully done business with each other before, they will have a lower level of uncertainty about the other party's performance and/or have a lower incentive to take measures to reduce the uncertainty they might experience. However, if the level of trust between parties is not sufficient, they can typically engage intermediaries, such as trusted third parties, who can provide additional assurances. Electronic markets can be viewed as such an intermediary, especially when the market is run by an entity that is trusted and respected by all its users. However, the intermediary will acquire a lot of information about users and their transactions and will be in a position to benefit from this.

Blockchain technology started as a way to eliminate such intermediaries and replace trust in a central organization or intermediary with trust in technology. Trust can be completely transferred, in case of distributed autonomous organizations, allowing the "implementation of decentralized market systems without intermediaries at reasonable conditions" (Alt 2018). Wigand (2020) stresses the essential relevance of electronic markets as a vehicle for disintermediation, with the potential to then function as a "form of reintermediation" in this context. Alternatively, a partial transfer of trust can occur at "only" the transactional level, when "classical" intermediaries adopt and run Blockchain applications to make their coordination tasks more efficient and effective, but also more transparent and with fairer revenue distribution in case the platform itself generates a profit.
The first aspect is at the core of the article "Understanding the creation of trust in cryptocurrencies: the case of Bitcoin" by Venkata Marella, Bikesh Upreti, Jani Merikivi and Virpi Kristiina Tuunainen (2020). Although a lot of research exists on trust and cryptocurrencies, the underlying attributes of the technologies that drive this trust are not well understood. They present the results of a text modelling study of close to two million articles on Bitcoin, the oldest Blockchain platform and cryptocurrency. Using functionality, reliability and helpfulness as focal constructs, they discovered 11 different attributes related to three technology constructs that are significant in creating and maintaining users' trust in Bitcoin. Their findings might well be transferred beyond cryptocurrencies into other Blockchain-based platforms, which have to overcome the "trust in technology" issue during these still early days of decentralized electronic market platforms.

The aspect of reaching a fairer distribution of value is reflected in the second article in this cluster, "Toward a renaissance of cooperatives fostered by Blockchain on electronic marketplaces: a theory-driven case study approach" by Tobias Kollmann, Simon Hensellek, Katharina de Cruppe and André Sirges (2020). They investigate how the value generated by the market platform itself is distributed between the usually centralized operator of the platform on the one hand and its users on the other hand. The value is generated from collecting and matching electronic information from the users, but they only receive a small share. Through a theory-driven case study, the article investigates how the potential disruptive properties of "Blockchain Enabled Electronic Markets" can foster a renaissance of cooperative principles in electronic markets.

\section{Taxonomies of business models as a result of blockchain technology}

The two remaining articles in this Special Issue both develop a taxonomy to address different aspects of Blockchain-based business model innovation. The first article, "The impact of blockchain technology on business models - a taxonomy and archetypal patterns", by Jörg Weking, Michael Mandalenakis, Andreas Hein, Sebastian Hermes, Markus Böhm and Helmut Krcmar (2020) focuses at the implications of Blockchain technology on pre-existing business models, recognizing that research and practice are still at their infancy about altering existing and creating new business models. The article provides a taxonomy of five archetypical patterns, based on 99 Blockchain ventures and following the design science research methodology. The taxonomy should help firms by illustrating how the technology can innovate their business models.

The final article specifically addresses token-based business models and the associated initial coin offerings. In their article "Understanding token-based ecosystems - a taxonomy 
Table 1 Research method, scope, aspect and deliverable of the articles

\begin{tabular}{|c|c|c|c|c|}
\hline Article & $\begin{array}{l}\text { Research } \\
\text { Method }\end{array}$ & Scope & Aspect & Deliverable \\
\hline $\begin{array}{l}\text { Albrecht } \\
\text { et al. } 2020\end{array}$ & $\begin{array}{l}\text { Text mining / } \\
\text { AI }\end{array}$ & $\mathrm{ICO}$ & $\begin{array}{l}\text { Effect of } \\
\text { communication } \\
\text { about ICO }\end{array}$ & $\begin{array}{l}\text { Recommended } \\
\text { communication aspects }\end{array}$ \\
\hline $\begin{array}{l}\text { Bauer et al. } \\
2020\end{array}$ & $\begin{array}{l}\text { Design } \\
\text { Science }\end{array}$ & $\begin{array}{l}\text { Electronic } \\
\text { market } \\
\text { efficiency }\end{array}$ & $\begin{array}{l}\text { Information asymmetry } \\
\text { and uncertainty }\end{array}$ & $\begin{array}{l}\text { Verification of Blockchain } \\
\text { impact }\end{array}$ \\
\hline $\begin{array}{l}\text { Kollmann } \\
\text { et al. } 2020\end{array}$ & $\begin{array}{l}\text { Theory driven } \\
\text { case study }\end{array}$ & $\begin{array}{l}\text { Blockchain } \\
\text { enabled EM }\end{array}$ & $\begin{array}{l}\text { Business Model / Value } \\
\text { Distribution }\end{array}$ & $\begin{array}{l}\text { Applicability cooperative } \\
\text { model }\end{array}$ \\
\hline $\begin{array}{l}\text { Marella et al. } \\
2020\end{array}$ & $\begin{array}{l}\text { Text modelling } \\
\text { / AI }\end{array}$ & $\begin{array}{l}\text { Technical } \\
\text { attributes } \\
\text { Bitcoin }\end{array}$ & Ability to create trust & $\begin{array}{l}\text { Technology constructs and } \\
\text { attributes }\end{array}$ \\
\hline Ostern 2020 & $\begin{array}{c}\text { Theoretical } \\
\text { review }\end{array}$ & $\begin{array}{r}\text { Blockchain } \\
\text { literature }\end{array}$ & $\begin{array}{l}\text { Definitions and } \\
\text { terminology }\end{array}$ & Key issues for IS Research \\
\hline $\begin{array}{l}\text { Tönnissen } \\
\text { et al. } 2020\end{array}$ & $\begin{array}{l}\text { Taxonomy } \\
\text { develop- } \\
\text { ment }\end{array}$ & $\mathrm{ICO}$ & Information asymmetry & Taxonomy and archetypes \\
\hline $\begin{array}{l}\text { Weking et al. } \\
2020\end{array}$ & $\begin{array}{l}\text { Design } \\
\text { Science }\end{array}$ & $\begin{array}{c}\text { Blockchain } \\
\text { ventures }\end{array}$ & Business Model & Taxonomy and archetypes \\
\hline $\begin{array}{l}\text { Zavolokina } \\
\text { et al. } 2020\end{array}$ & Mixed method & $\begin{array}{l}\text { Electronic } \\
\text { market } \\
\text { efficiency }\end{array}$ & $\begin{array}{l}\text { Information seeking } \\
\text { process }\end{array}$ & $\begin{array}{l}\text { Requirements on } \\
\text { Blockchain } \\
\text { implementation }\end{array}$ \\
\hline
\end{tabular}

of blockchain-based business models of start-ups", Stefan Tönnissen, Jan Heinrich Beinke and Frank Teuteberg (2020) also address the Initial Coin Offering phenomenon as a crowdfunding mechanism for Blockchain-based start-ups. They start from the realization that despite the increasing investments in ICOs, there is still a lack of understanding and theoretical foundations on how they work in practice. They investigate the business model forms and their influence on collaboration in token-based economies and develop a taxonomy of real-world Blockchain-based startups, based on cluster analysis of 195 start-ups. The article presents the resulting three archetypes as strategic guidance for practitioners as well as a starting point for future research.

\section{Research methodology}

It is a good tradition at the Electronic Markets journal to promote various research methods, given the variety of research domains and disciplines that come in play when investigating electronic markets and networked business. This Special Issue is a good example of the resulting diversity in research methodologies.

Nadine Ostern (2020) applies a theoretical literature review to identify three issues that need to be clarified by IS Research. Kollmann et al. (2020) use a theorydriven case study approach to consider principles of cooperative theory as a foundation of Blockchain enabled electronic marketplaces. The design science approach (Hevner et al. 2004) is used by Bauer et al. (2020) to create a market game to explore the effect of trusted data in a used car market. Design science is also used by Weking et al. (2020) to develop a taxonomy of Blockchain business models and associated archetypical patterns. Tönnissen et al. (2020) also develop a taxonomy but follow the method by Nickerson et al. (2013) to analyze Blockchain-based start-ups and tokenbased ecosystems. A mixed qualitative and quantitative method is used by Zavolokina et al. (2020) to analyze the information seeking process and to derive Blockchain design requirements.

Finally, Artificial intelligence has been applied as a research method in two articles. Albrecht et al. (2020) combine a text mining approach on 144,942 tweets with a subsequent regression analysis to test their hypotheses on the effect of language, interactivity and frequency in communications about ICOs. Marella et al. (2020) apply text modelling of 1.97 million discussion posts related to Bitcoin, using vector representations of words and documents and a neural network to identify semantic similarities

In Table 1, we have summarized the key characteristics of the eight articles in this Special Issue.

\section{Conclusions}

When we issued our Call for Papers in 2018, there was little research on the relevance of the Blockchain technology on electronic markets and networked businesses. Most publications were of a technical nature, discussing the various cryptographic methods for consensus mechanisms, scalability and 
ecological footprint. Business applications focused at the effects of cryptocurrencies or the possibility to eliminate intermediaries. We hoped to attract contributions that would be less focused on the origin of the first Blockchains and the associated bias towards public Blockchains to eliminate banks, governments and other intermediaries. Instead, we looked for articles that would highlight the opportunities the technology offers to improve the inter-organizational coordination in terms of efficiency, effectiveness and transparency.

We are pleased with the mix of articles the authors have submitted and we have been able to bring together in this special issue. This collection of articles provides guidance to promote further Blockchain research. The role and working of initial coin offerings as a crowdfunding mechanism are explored and it is shown how they typically work and what role communication can play to stimulate such investments. The possible impact of Blockchain on pre-existing business models is analyzed, as well as the role of Blockchain in reducing the information asymmetry and uncertainties within electronic markets, including specific recommendations on how to make the market mechanisms more efficient, effective and transparent. In case the Blockchain-based platform should take over the role of a trusted intermediary, key components to create and maintain trust have been identified. Finally, conceptual issues with IS Research have been identified that cause a conceptual fuzziness and prevent researchers from making compelling use cases for Blockchain innovations.

We did not manage to attract contributions on all topics we suggested in our Call for Papers. In particular, the possibilities of Blockchain technology for reducing overhead and friction between organizations was not addressed by the contributions we received. The interorganizational coordination of transactions traditionally requires a significant amount of redundancy, with all organizations trying to keep track of the current status of the transaction by communicating intensively and continuously updating each of their respective systems (Bons et al. 1998). Blockchains provide for unequivocal and indisputable records of what has occurred, providing a single and accessible "truth" to all stakeholders involved. And with the emergence of "smart contracts", the actual execution of (parts of the transaction) might be automated as well, reducing or even eliminating the need for back-office operations. Provided, that a sufficient level of standardization can be obtained to prevent a proliferation of platforms companies would have to participate in.

In conclusion, we feel that this Special Issue does show that there is a role for Blockchain and Distributed Ledger Technologies in electronic markets and networked businesses. We hope that the insights presented in the articles provide the relevance to guide businesses in determining if the technology is relevant for them. We also hope that the methodological variety reflected in this collection inspires IS and other researchers to investigate and study this phenomenon even further. We thank all the authors, who have submitted their papers to this Special Issue and hope to have provided valuable feedback, especially when we were not able to accept the paper for publication. We thank all the reviewers for helping us in doing so.

Funding Information Open Access funding provided by Projekt DEAL.

Open Access This article is licensed under a Creative Commons Attribution 4.0 International License, which permits use, sharing, adaptation, distribution and reproduction in any medium or format, as long as you give appropriate credit to the original author(s) and the source, provide a link to the Creative Commons licence, and indicate if changes were made. The images or other third party material in this article are included in the article's Creative Commons licence, unless indicated otherwise in a credit line to the material. If material is not included in the article's Creative Commons licence and your intended use is not permitted by statutory regulation or exceeds the permitted use, you will need to obtain permission directly from the copyright holder. To view a copy of this licence, visit http://creativecommons.org/licenses/by/4.0/.

\section{References}

Albrecht, S., Lutz, B., \& Neumann, D. (2020). The behavior of blockchain ventures on twitter as a determinant for funding success. Electronic Markets, 30(2). https://doi.org/10.1007/s12525-01900371-w.

Alt, R. (2018). Electronic Markets and current general research. Electronic Markets, 28, 123-128. https://doi.org/10.1007/s12525018-0299-0.

Bauer, I., Zavolokina, L., \& Schwabe, G. (2020). Is there a market for trusted car data? Electronic Markets, 30(2). https://doi.org/10.1007/ s12525-019-00368-5.

Bons, R. W. H., Lee, R. M., \& Wagenaar, R. W. (1998). Designing trustworthy interorganizational trade procedures for open electronic commerce. International Journal of Electronic Commerce, 2(3), 61-83. https://doi.org/10.1080/10864415.1998.11518316.

Diedrich, H. (2016). Ethereum: Blockchains, digital assets, smart contracts, decentralized autonomous organizations. Wildfire Publishing.

Hevner, A. R., March, S. T., \& Park, J. (2004). Design science in information systems research. MIS Quarterly, 28(1), 75-105. https://doi. org/10.2307/25148625.

Kollmann, T., Hensellek, S., De Cruppe, K., \& Sirges, A. (2020). Toward a renaissance of cooperatives fostered by Blockchain on electronic marketplaces: A theory-driven case study approach. Electronic Markets, 30(2). https://doi.org/10.1007/s12525-019-00369-4.

Marella, V., Upreti, B., Merikivi, J., \& Tuunainen, V. (2020). Understanding the creation of trust in cryptocurrencies: The case of bitcoin. Electronic Markets, 30(2). https://doi.org/10.1007/ s12525-019-00392-5.

Mayer, R. C., Davis, J. H., \& Schoorman, F. D. (1995). An integrative model of organizational trust. Academy of Management Review, 20(3), 709-734. https://doi.org/10.5465/amr.1995.9508080335.

McKnight, D. H. (2005). Trust in information technology. The Blackwell encyclopedia of management, Management Information Systems, 7, 329-331. Malden :Blackwell.

Nakamoto, S. (2008). Bitcoin: A peer-to-peer electronic cash system. https://www.bitcoin.org/bitcoin.pdf.

Nickerson, R. C., Varshney, U., \& Muntermann, J. (2013). A method for taxonomy development and its application in information systems. 
European Journal of Information Systems, 22(3), 336-359. https:// doi.org/10.1057/ejis.2012.26.

Ostern, N. (2020). Blockchain in the IS research discipline: A discussion of terminology and concepts. Electronic Markets, 30(2). https://doi. org/10.1007/s12525-019-00387-2.

Rousseau, D. M., Sitkin, S. B., Burt, R. S., \& Camerer, C. (1998). Not so different after all: A cross-discipline view of trust. Academy of Management Review, 23(3), 393-404. https://doi.org/10.5465/amr. 1998.926617.

Tönnissen, S., Beinke, J. H., \& Teuteberg, F. (2020). Understanding token-based ecosystems - A taxonomy of blockchain-based business models of start-ups. Electronic Markets, 30(2). https://doi.org/ 10.1007/s12525-020-00396-6.

Weking, J., Mandalenakis, M., Hein, A., Hermes, S., Böhm, M., \& Krcmar, H. (2020). The impact of blockchain technology on business models - A taxonomy and archetypal patterns. Electronic Markets, 30(2). https://doi.org/10.1007/s12525-019-00386-3.

Wigand, R. T. (2020). Whatever happened to disintermediation? Electronic Markets, 30(1), 1-9 https://doi.org/10.1007/s12525019-00389-0.

Wohlgemuth, S., Sackmann, S., Sonehara, N., \& Tjoa, A. M. (2014). Security and privacy in business networking. Electronic Markets, 24, 81-88 https://doi.org/10.1007/s12525-014-0158-6.

Zavolokina, L., Miscione, G., \& Schwabe, G. (2020). Buyers of 'lemons': How can a blockchain platform address buyers' needs in the market for 'lemons'? Electronic Markets, 30(2). https://doi.org/10.1007/ s12525-019-00380-9.

Publisher's note Springer Nature remains neutral with regard to jurisdictional claims in published maps and institutional affiliations. 